\title{
O EQUILÍBRIO PRECÁRIO ENTRE ARTE E REALIDADE: EM ABEL AZCONA
}

\author{
Djalma Thürler ${ }^{1}$ \\ Duda Woyda ${ }^{2}$
}

\begin{abstract}
Resumo: $\mathrm{O}$ artigo, fruto de pesquisa sobre as infiltrações da performance no teatro contemporâneo, produzido na encruzilhada entre Arte, Ciências Sociais e Humanas, busca explorar as relações entre o teatro, corpo e colonialidade, a partir do trabalho realizado em duas obras do artista espanhol Abel Azcona, a saber, "España os pide perdón" e "Empatía y Prostitución". Para pensar a experiência da decolonialidade na arte, optamos por intelectuais de caráter heterogêneo e transdisciplinar, dentre os quais Paul B. Preciado, Suely Rolnik e Rancière. Espera-se constatar que Azcona, enquanto artista contemporâneo, acredita na arte como um instrumento transformador, útil para a revolução micropolítica pensada por Preciado e que as obras autobiográficas aqui abordadas possuem marcadores políticos que expressam uma profunda rebelião contra a sociedade.
\end{abstract}

Palavras-chave: Arte contemporânea. Abel Azcona. Sexualidade. Decolonialidade.

\section{EL PRECARIO EQUILIBRIO ENTRE EL ARTE Y LA REALIDAD: EN ABEL AZCONA}

\begin{abstract}
Resumen: El artículo, fruto de la investigación sobre las infiltraciones de la performance en el teatro contemporáneo, pensado en la encrucijada entre el arte, las ciencias sociales y humanas, busca explorar las relaciones entre el teatro, el cuerpo y la colonialidad, partiendo del trabajo realizado en dos obras del artista español Abel Azcona, a saber, "España os pide perdón" y "Empatía y Prostitución". Para pensar en la experiencia de la descolonialidad en arte, elegimos intelectuales de carácter heterogéneo y transdisciplinario, entre ellos Paul B. Preciado, Suely Rolnik y Rancière. Se espera que Azcona, como artista contemporáneo, crea en el arte como instrumento transformador, que sea utilizado para la revolución micropolítica pensada por Preciado y que las obras autobiográficas que aquí se discuten tengan marcadores políticos que expresen una profunda rebelión contra la sociedad.
\end{abstract}

Palabras clave: Arte contemporáneo. Abel Azcona. Sexualidad. Descolonialidad.

\footnotetext{
${ }^{1}$ Professor do Programa de Pós-Graduação em Cultura e Sociedade da Universidade Federal da Bahia (UFBA) e Diretor artístico da ATeliê voadOR Teatro: djalmathurler@uol.com.br.

2 Doutorando do Programa de Pós-Graduação em Cultura e Sociedade da Universidade Federal da Bahia (UFBA). Ator e investigador da ATeliê voadOR Teatro. E-mail: dudawoyda@gmail.com.
} 
"O que vou lhes contar, não o direi de minha cabeça; não fiz mais que retranscrever o que já estava escrito, ou o que já estava dito num manuscrito que encontrei e em confidências que surpreendi ou ouvi. Não sou eu quem falo, é um outro. E é esse outro que coloco em cena" (FOUCAULT, 2016, p. 143). Segundo Foucault, assim era a tradição dos romances do século XVIII, que anunciavam a própria narrativa sob um véu de verossimilhança. É dessa forma que Foucault inicia sua primeira sessão sobre os escritos de Sade. É dessa forma que iniciamos nosso ensaio.

Esse texto se debruça sobre duas obras de Abel Azcona (Pamplona/1988), “España os pide perdón” e "Empatía y Prostitución” que, juntas, poderiam funcionar como "um guia de resistência micropolítica em tempos de contrarrevolução" (PRECIADO, 2018a, p. 12) e desenvolver a ideia de Rancière, que estabelece as coordenadas sobre o regime estético da arte a partir das quais politizar a arte não visa fazer da arte precisamente o que falta à política ("estetização da política"), a fim de criar uma mobilização eficaz em um mundo amplamente desencantado com a política (RANCIÈRE, 2009).

Embora concordemos com Augusto Boal, que "a arte apresenta sempre uma visão de mundo em transformação e, portanto, é inevitavelmente política, ao apresentar os meios de realizar essa transformação" (BOAL, 2013, p. 30), na contemporaneidade tem sido difícil entender a relação entre arte e política de forma que ela não se resuma à prática artística como forma inovadora de alcançar certa identidade política, ou "porque mostra os estigmas da dominação, [ou] porque ridiculariza os ícones reinantes ou por que sai de seus lugares próprios para transformar-se em prática social etc" (RANCIÈRE, 2012, p. 52).

De outro modo, é igualmente difícil perceber a capacidade da arte de interferir em macropolíticas sem pensar na questão da "eficácia de uma distância e de uma neutralização" (idem, p. 56). A distância defendida por pensadores como Rancière não é a de ignorar o político, pelo contrário, consiste em saber que toda crítica precisa de distância e que o que é realidade não é algo dado de antemão, mas sim algo construído de uma forma imanente ao próprio discurso ético-estético-político, espécie de "invenção da natureza" 
(SEGATO, 2018). Por outras palavras, cada exercício eficaz de resistência política consiste em mediar outra distância, outra suspensão onde o sujeito/objeto dialético nunca encontraria reconciliação - pois isso seria um sintoma de ter sido subsumido por uma razão utilitária, fetichista e cafetinada (ROLNIK, 2008).

Se a realidade é, portanto, uma construção social elaborada de forma crítica, o que estaria em causa seria minar essa realidade disposta de forma consensual e normativa, fracioná-la e multiplicá-la de uma forma controversa. A relação entre arte e política não é, portanto, a de permitir uma passagem da ficção artística à realidade, não se trata de se inserir no real ou de revelar o falso no mundo real, como exemplifica Rancière acerca da clássica cena teatral que "deveria ser um espelho ampliador em que os espectadores eram convida dos a ver, nas formas da ficção, os comportamentos, as virtudes e os vícios humanos" (RANCIÈRE, 2012, p. 53); muito pelo contrário, trata-se de violar os pressupostos do real a partir de dentro, do exercício, da criação de um dispositivo ético-estético-político destinado a criar dissensos, fratura no campo do já dado, do ontológico, afinal a

ficção não é criação de um mundo imaginário oposto ao mundo real. E o trabalho que realiza dissensos, que muda os modos de apresentação sensível e as formas de enunciação, mudando quadros, escalas ou ritmos, construindo relac ões novas entre a aparência e a realidade, o singular e o comum, o visível e sua significação (RANCIÈRE, 2012, p. 64).

Dois eixos-chave carregam os parâmetros que definem a abordagem de Rancière à arte. O primeiro eixo é constituído pelo seu conhecido relato da modernidade estética como um "regime das artes" democrático, que rompe com o anterior, "representativo", ao permitir que todos os sujeitos e todos os gêneros sejam apropriados em gestos expressivos. Estes gestos expressivos já não podem contar com as velhas regras e referências de representação e, por conseguinte, exigem formas criativas constantemente reinventadas. O segundo eixo emerge do desmantelamento do antigo regime de representação. É, portanto, um novo modo de criatividade expressiva inerente à ação individual e coletiva. A combinação destes dois princípios cria 
as condições estruturais e as contradições do campo estético moderno, dentro do qual os artistas individuais definem as suas tarefas e encontram novos limites e dificuldades.

Abel Azcona é certamente um dos jovens artistas com maior projeção internacional, convidado de inúmeros museus, galerias e festivais internacionais e, também, muito apreciado no contexto da América Latina ${ }^{3}$. Numa época em que as previsões de Guy Debord (1997) foram confirmadas (tudo pode ser transformado em um espetáculo), parte dos críticos tem considerado seu trabalho como exibicionismo livre, embora para muitos outros tenha uma base introspectiva importante, uma vez que o artista usa a história da sua vida para se libertar das correntes do passado que o marcam até aos dias de hoje, como a prostituição da sua mãe, um pai desconhecido, a violência e a discriminação sexual, dias passados numa clínica psiquiátrica e várias tentativas de suicídio. A verdade é que, além de um contínuo exercício de autoconhecimento, todos os seus projetos autobiográficos tornam-se metadiscurso crítico a explorar alguns temas como abuso infantil, feminismo, sexualidade, desigualdades, política ou religião. Esses elementos são reunidos naquilo que para Azcona é o que acredita ser a função da arte, uma "prática política de subjetivação dissidente" (PRECIADO, 2018a, p. 16), de denúncia social e de exploração de outras subjetividades.

Por acreditar que poucas armas são mais políticas que o próprio corpo, é o seu corpo que, na maior parte das vezes, é utilizado como o principal instrumento para suas performances, sempre estimulantes, desafiantes e excitantes, um corpo-manifesto intencionalmente provocativo, causador de alguma modificação, alguma transformação no espectador. Aliás, Azcona prefere, o que ele chama de visitante ativo - aquele espectador que se irrita, que grita, que vomita ao vê-lo, que se escandaliza, que sai da galeria aos gritos, que denuncia - ao espectador que o aplauda. Essas reações que Azcona espera do seu visitante ativo não são difíceis de serem alcançadas, basta pensar nas

\footnotetext{
${ }^{3}$ Segundo o site https://desdemisarrugascerebrales.wordpress.com/2014/04/07/abel-azcona-empatia-yprostitucion/, Azcona já expôs em seu trabalho em países como Espanha, Portugal, França, Itália, Dinamarca, Reino Unido, Alemanha, Grécia, Polônia, México, Venezuela, Equador, Peru, Argentina, Estados Unidos, Colômbia, China, Filipinas e Japão.
} 
provocações causadas por Amém, performance na qual formou a palavra pederastia com hóstias consagradas.

Em resposta à repercussão conservadora e midiática de algumas de suas ações, Azcona teorizou sobre a capacidade catártica e discursiva de suas performances no manifesto artístico “Teoria Involuntária de uma Morte Confrontada" ${ }^{4}$ (ITPD), assinado e apresentado em março de 2013, no Círculo de Bellas Artes, em Madrid. O manifesto é uma declaração sobre a elevação do conceito, a preeminência da ideia que impulsiona a ação e expõe a luta individual contra certas situações sociais, uma forma de denúncia sobre o regime "heteropatriarcal, colonial e neonacionalista" (PRECIADO, 2018a, p. 11). Todo o Manifesto é abordado em uma perspectiva muito humana, uma vez que, como mostra um de seus fundamentos, o número VI, o instinto de sobrevivência que nos acompanha pelo simples fato de sermos humanos, deve prevalecer.

\section{A espanha e os traumas coloniais}

Enquanto continua a pensar em trabalhos políticos e polêmicos, como é o caso de "España os pide perdón", Abel Azcona planeja seu projeto mais importante, sua própria morte: “Minha morte virá em breve e será um processo artístico" (PARDO, 2020, s/d).

Em “España os pide perdón”, obra criada e iniciada em Bogotá em novembro de 2018 e que ainda avançará por cidades da América Latina, o que se busca é abrir um debate, uma reflexão sobre a posição da Espanha diante do colonialismo atual, ação que coaduna com um movimento internacional, uma vez que obras e ações contra o colonialismo ganham força na academia e nas artes em todo o mundo, problematizando estruturas eurocêntricas, entre elas a colonialidade triangular do ser, do saber e do poder. Sobre a diferença entre colonialismo e colonialidade, Castro-Goméz e Grosfoguel, explicam:

Nosotros partimos, en cambio, del supuesto de que la división internacional del trabajo entre centros y

\footnotetext{
${ }^{4} \mathrm{O}$ manifesto original foi produzido conjuntamente com o artista Omar Jerez e pode ser consultado em: https://www.plataformadeartecontemporaneo.com/pac/presentacion-internacional-del-manifiestoartistico-teoria-involuntaria-de-una-muerte-confrontada/.
} 
periferias, así como la jerarquización étnico-racial de las poblaciones, formada durante varios siglos de expansión colonial europea, no se transformó significativamente con el fin del colonialismo y la formación de los Estadosnación en la periferia. Asistimos, más bien, a una transición del colonialismo moderno a la colonialidad global, proceso que ciertamente ha transformado las formas de dominación desplegadas por la modernidad, pero no la estructura de las relaciones centro-periferia a escala mundial (CASTRO-GOMÉZ; GROSFOGUEL, 2007, p. 13).

Por colonialidade, então, nos referimos "ao vínculo entre o passado e o presente, no qual emerge um padrão de poder resultante da experiência moderna colonial, que se moldura no conhecimento, na autoridade, no trabalho e nas relac ões sociais intersubjetivas (STREVA, 2016, p. 21), na continuação do exercício atemporal de poder articulado de forma binária e hierárquicas na construção de nossas subjetividades, desde o encobrimento do outro (DUSSEL, 1993) até a contemporaneidade, “logo, este conceito não se limita ao período de colonização, mas implica na continuidade de formas coloniais de dominação após o fim da colonização" (STREVA, idem), se refere ao processo contínuo e intensivo de dominação e exploração geográfica, política, econômica, cultural e epistemológica.

Seguindo esse pensamento, Azcona compreende que a Espanha deve pedir desculpas às suas colônias pelos traumas coloniais (SIMAS; RUFINO, 2019, p. 13), pelos crimes contra a sua cultura, tais como genocídio, tráfico de escravos, exploração dos recursos naturais, doenças e destruição do seu patrimônio. Foi com essa intenção, a de compreender o "colonialismo como espectro do terror, política de morte e desencanto que se concretiza na bestialidade, no abuso, na produção incessante de trauma e humilhação" (idem, p. 12) que, em junho de 2020, a estátua do escravocrata britânico Edward Colston foi jogada nas águas do porto de Bristol, na Inglaterra. É preciso lembrar que após o assassinato de George Floyd, nos Estados Unidos, e das inúmeras manifestações do black lives matter, o movimento contra as estátuas ligadas ao colonialismo/colonialidade e à escravidão cresceu nos EUA e se expandiu pelo mundo. 
A ação, segundo reportagens como "Derrubar estátuas, reescrever a História", da Mídia Ninja, inspirou e segue inspirando outras derrubadas de monumentos de figuras coloniais em vários países:

Derrubar uma estátua é também uma maneira de incentivar debates sobre o tema e divulgar o movimento. O próprio vídeo se torna um documento histórico com seu valor próprio e a queda da estátua acrescenta detalhes tanto na história da escravidão quanto na história contemporânea (Mídia Ninja, 2020, s/p).

Ainda segundo a matéria da Mídia Ninja, "ao longo da história, existiram três maneiras de se lidar com os chamados 'monumentos polêmicos': retirar completamente os monumentos, retirar as estátuas e deixar os pedestais, ou simplesmente mantê-los" (idem). Concordando com a matéria da Mídia Ninja, a jornalista Waafa Albadry, em sua coluna "Let's topple statues to decolonize", o derrubamento de estátuas não apaga a história, "é antes um protesto político contra a celebração de uma história ou presente comuns, em que um lado ainda sofre as consequências daquela história”'5 (ALBADRY, 2020, s/p).

Na contramão desse entendimento, uma carta assinada por mais de 150 escritores, acadêmicos e intelectuais, publicada em 07 de julho de 2020, reconhece a legitimidade dos protestos em prol da justiça racial e social, bem como os apelos mais amplos para discutirmos a igualdade e a inclusão em nossa sociedade, no entanto destacam que esse reconhecimento também intensificou um novo conjunto de atitudes morais e compromissos políticos que tendem a enfraquecer e restringir o debate ${ }^{6}$.

Abel Azcona acredita que algumas obras de arte existem para lembrar, precisamente, aquilo que se quer esquecer e, por isso não acha que derrubar estátuas seja a ação decolonial mais potente e encontra outras

\footnotetext{
${ }^{5}$ rather, it is a political protest against the celebration of a common history or present, where one side is still suffering the consequences of that history - Tradução nossa.

${ }^{6}$ A matéria na íntegra pode ser lida em https://harpers.org/a-letter-on-justice-and-open-debate/. Acesso em 08 jul. 2020. Antes do fechamento deste artigo, a escultura de Edward Colston fora substituída em 15 julho de 2020 pela estátua de uma mulher negra com o punho erguido no ar em homenagem a Jen Reid, manifestante fotografada sobre o pedestal onde ficava a estátua de Colston.
} 
brechas de engendrar um discurso, um debate com base decolonial, como tem feito em toda a sua obra, seja

através do uso de manifestos, de uma gama de estratégias políticas e de novas tecnologias de representação, utopistas radicais continuam a procurar diferentes maneiras de ser no mundo e de ser em relação um com o outro do que aquelas prescritas para o sujeito liberal e consumidor (HALBERSTAM, 2020, p. 20).

Em maio de 2020, portanto, não derrubara literalmente nenhuma estátua, mas entrou no debate decolonial quando Havana acordou com seu último trabalho. A mensagem "España os pide perdón” pode ser lida em uma multidão de cartazes que encheram a capital de Cuba e devem ser levadas, ainda, para cerca de 20 cidades onde a Espanha deixou sua marca colonial.

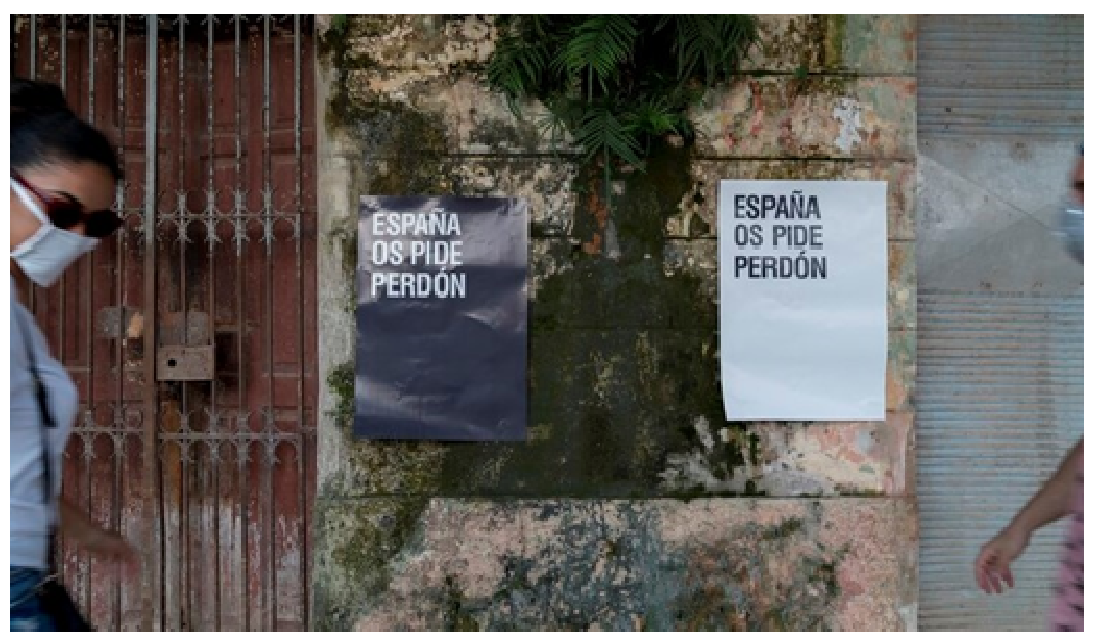

Estudio Abel Azcona twitter

A arte inadequada (HALBERSTAM, 2020) de Azcona é múltipla e variada, vai desde a performance até instalações, esculturas, arte em vídeo, pintura ou escrita, com obras literárias que vão desde ensaios a textos literários ou memoriais, como foi o caso de "Los pequeños brotes" (2019), mas todos com um agudo caráter crítico, político e social e, certamente, nenhum deles deixará o espectador indiferente. 
"España os pide perdón" por exemplo, gera um debate atual sobre a violência cometida pelos países europeus durante a invasão colonial e nos permite, ao menos, duas indagações: Qual o papel que a Espanha tem desempenhado na América Latina enquanto instância colonizadora em disputas políticas pelo imaginário social e, uma segunda, decolonialmente, como e de que maneira escancaramos as consequências do colonialismo eurocêntrico e resgatamos uma identidade silenciada?

“España os pide perdón” é uma intervenção urbana, um trabalho de instalação em que esta frase é inserida no dia a dia do cidadão, seja através de cartazes, instalações, banners, anúncios e pinturas nas próprias fachadas dos museus mais importantes de cada capital latino-americana, uma modalidade da arte contemporânea que acredita na capacidade crítica e reflexiva do público,

pois pede uma interpretação ativa, pode unir diversos meios de pensamento, relacionar-se a vários contextos e é suscetível a múltiplas interpretações, promovendo o tipo de entendimento exigido por uma sociedade pluralista, nas quais grupos podem coexistir com diferentes histórias, valores e pontos de vista (FONSECA, 2007, p. 40).

Para Cristina Híjar (2020), diferentes termos foram elencados para tentar capturar esse movimento nas Artes: arte política, arte militante, arte urgente, arte participativa, arte relacional, artivismo, etc., mas considera que cada uma dessas denominações pode ser útil e justificada, aplicada a situações e análises específicas, dependendo da ênfase que se busca. Para a autora, o que importa

es responder a las preguntas de por qué, desde dónde, cómo, con y para quién se produce todo este universo de significación que nos circunda y afecta de muy diversas maneras en un momento histórico en el que compartimos, a escala mundial, los mismos problemas, los mismos agravios, las mismas preocupaciones, sujetos a un orden mundial de despojo en el que todos somos desechables en función de la máxima ganancia económica para una "clase mundial" que no entiende ni le importa la lucha por la vida emprendida por quienes no se 
conforman y no se resignan a un único y desastroso futuro posible para la mayoría (HÍjAR, 2020, p. 7).

Azcona, com "España os pide perdón" opta pela convergência entre a arte e o ativismo como uma ferramenta de catarse e empoderamento numa obra crítica, irônica e provocadora que acredita na reparação, na reconstrução da história:

A veces hay que reabrir la historia, reconstruirla y repararla en común... Desde luego, la palabra 'perdón' tiene esa parte irónica de que el perdón muy cristiano y muy católico, y justamente esa herencia de esta invasión que fue patriarcal, evangelizadora, católica... Utilizar esta palabra que ellos mismos usan con un afán católico, me parecía que tenía ese punto de doble sentido. Me parece una metáfora bela (DDC, 2020, s/p).

Para o artista, este debate deveria ter sido encerrado a mais de 500 anos, pois o perigo de uma única história (CHIMAMANDA, 2019) impediu que a América Latina pudesse reconhecer o carrego colonial (SIMAS; RUFINO, 2019, p. 22) e que nunca houve glória alguma a ser comemorada, mas, ao contrário, violência/terror despossessão, extrativismo, "assassinato, cárcere, tortura, desmantelo cognitivo e domesticação dos corpos, [...] desarranjo das memórias e saberes ancestrais" (Idem, p. 20) e, mais, que esse investimento na "produção do esquecimento" (idem, p. 20) tem sido parte importante do terror do colonialidade até hoje. É por isso que "España os pide perdón” tem papel importante enquanto uma obra que cria diálogos entre a cidade e a história, analisando os discursos hegemônicos como dispositivos para apoiar seus preconceitos que identificam a fé católica com a civilização e, ainda, fazendo a sociedade pensar criticamente essa relação, em por que ainda existem avenidas em cidades como Madri e Barcelona com os nomes de Pizarro e Colón? E por que o dia 12 de outubro é a data em que se comemora o Dia Nacional da Espanha? Azcona acredita que é um assunto atual

y que hay que revisar para que la gente cuando camine por las calles de La Habana, Bogotá o Lima reflexione por qué todavía en España el 12 de octubre, Día de la Hispanidad, sigue siendo de celebración, cuando debería 
ser de pedir perdón por ese acto genocida que fue todo el colonialismo (HUERGA, 2020, s/p).

Para Azcona, a Espanha, que nunca condenou o franquismo, por exemplo, tem pouca memória histórica. A provocação de Azcona sobre civilização e barbárie segue avançando por outros países, como podemos notar na imagem "Monumento a Cristóvão Colombo", no centro da cidade de Bogotá.

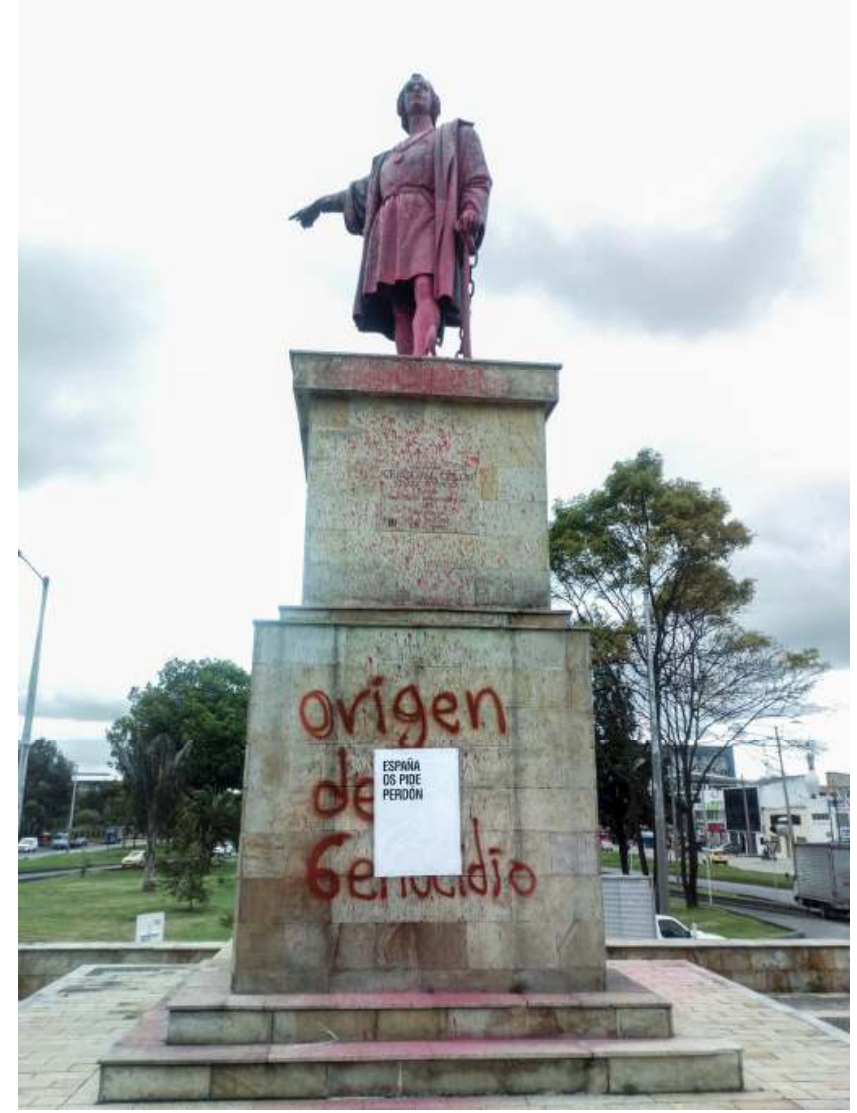

Estudio Abel Azcona twitter

Evidentemente a reação a "España os pide perdón” foi como Azcona esperava, uma vez que o artista "se alinha àqueles que procuraram sentimentos diversos do orgulho e da autoafirmação tão em voga partir dos 
anos 1960 nos movimentos minoritários" (LOPES, 2020, p. 14) e opiniões cheias de raiva e repugnância lotaram o twitter do artista, como podemos perceber nessa postagem:

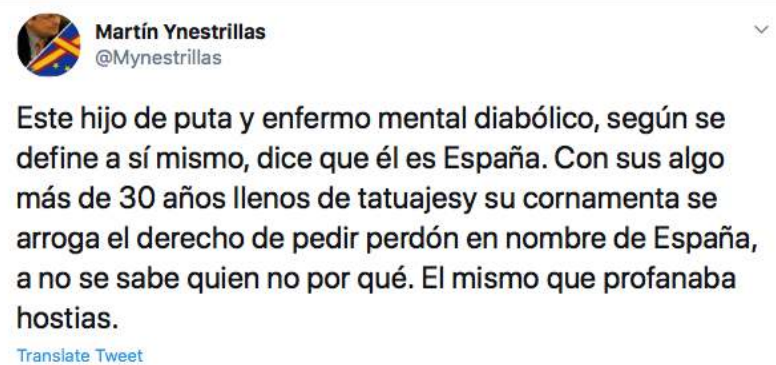

O leitor, nota-se, conhece a obra de Azcona, haja vista a referência que faz a "Amém", a obra que "profanaba hostias" e, também, a própria vida do artista, já que se utiliza da sua biografia para desqualificar sua obra. Mas o que mais chama a atenção nos comentários, é o debate sobre o status da arte contemporânea, originalmente iniciado por Marcel Duchamp e amparado pelas experiências dos seus ready-mades "Fontaine" (1917) e "Porte-bouteille" (1914), por exemplo. A assinatura do artista, que em boa hora sublinha que “isto é arte", coloca em perspectiva a famosa fórmula de Duchamp de que "é o espectador que faz a obra", por outras palavras, o artista reconhece o poder do espectador para dar sentido ao que lhe é dado ver. É o que acontece com Azcona quando utiliza do próprio corpo como suporte estÉtico, ou mesmo como uma mercadoria, como veremos em sua próxima obra.

\section{Empatia e prostituição - um corpo que obriga o espanto}

“Empatía y Prostitución” é uma ação performática concebida, desenvolvida e executada por Azcona nas cidades de Bogotá (Colômbia), Madrid (Espanha) e Houston (Estados Unidos), em três ciclos claramente diferenciados realizados durante os anos 2013 e 2014. O primeiro ciclo do projeto foi concebido e realizado na Galeria Santa Fé, em Bogotá, em fevereiro

7 Sobre esta obra, sugerimos a leitura de (cu)nhantã tem, (cu)rumim também: políticas de subjetivação em imagens de Abel Azcona (2020), de Djalma Thürler, Duda Woyda e Olinson Valois. 
de 2013. O segundo ciclo em Madrid pela Galería Factoría de Arte y Desarrollo, por ocasião da Salão de Arte de Madrid, no mesmo ano, e a terceira e última fase foi realizada em fevereiro de 2014 como peça de abertura da Bienal Internacional de Arte Performativa de Houston. A documentação, arquivo e instalações físicas de cada uma das três fases de "Empatia e Prostituição", ao longo de 2013 e 2014 geraram diferentes exposições e instalações em cidades como Pamplona, Madrid, Paris, Tirana, Bogotá, Cidade do México, Nova Iorque e Houston.

Néstor Llopis, curador e historiador da arte, da Universidade de Valência, apresentou desta forma o trabalho de Azcona:

Cien pesos colombianos, un euro o un dólar por tres minutos, con esta premisa encontramos al artista desnudo y tendido sobre una cama. Tres minutos en los que su cuerpo será propiedad de quien lo quiera y pague por él, tres minutos en los que crear un vínculo forzado es la única posibilidad de vínculo. Desarrollarse en un vientre propiedad del mejor postor, ser el resultado de un encuentro entre desconocidos cuyo nexo parte de una billetera, convierte un puñado de monedas y un cuerpo ofrecido como objeto (a)sexual en el medio de conexión. Un cuerpo atrofiado que no es capaz de encontrar vínculo alguno si no es mediante imposiciones, que desconoce el proceso de unión y empatía natural al ser educado como catalizador de deseos ajenos. La reproducción de su proceso de concepción, de las circunstancias y emociones que en él intervinieron, son el modo en el que Azcona establece esa conexión empática con su madre biológica (LLOPIS, s/d, s/p).

Artista hiperativo, que cria continuamente projetos que denunciam o cistema (GUZMÁN, 2014), em especial o fundamentalismo religioso, Abel Azcona assume, a cada novo trabalho, novos riscos. Neste trabalho, o seu corpo se transforma em uma instalação viva. O público o encontrava completamente nu e deitado em posição fetal no centro do que seria o seu quarto e numa cama, onde os sexpectadores (CORRONS, 2020) são convidados para uma experiência do espanto que 
requer parar para pensar, parar para olhar, parar para escutar, pensar mais devagar, olhar mais devagar, e escutar mais devagar; parar para sentir, sentir mais devagar, demorar-se nos detalhes, suspender a opinião, suspender o juízo, suspender a vontade, suspender o automatismo da ac,ão, cultivar a atenc,ão e a delicadeza, abrir os olhos e os ouvidos, falar sobre o que nos acontece, aprender a lentidão, escutar aos outros, cultivar a arte do encontro, calar muito, ter pacie`ncia e dar-se tempo e espac o (LARROSA, 2015, p. 25).

Dessa cama, com lençóis brancos, ele desafia o espectador a deixar de ser um estranho voyerista e a tornar-se parte da obra de arte com ele, podendo fazer com seu corpo o que quisessem, enquanto o resto da audiência assistia. Talvez seja importante frisar que a opção pela cor branca nos lençóis tenha servido para dar à ação performativa uma atmosfera particular, que representasse o estado psicológico, o seu mundo psíquico e, também, a criação de outros espaços, de heterotopias, ou seja, lugares onde uma utopia é realmente realizada ${ }^{8}$, espaços em branco que permitem qualquer escritura, a janela aberta para a realização da imaginação sexual e suas das fantasias e prazeres.

O corpo de Azcona transforma o espectador em verdadeiro "performer" e com essa mudança de papéis, procura empatia, a construção de algum vínculo, não apenas com a sua mãe, mas também com o próprio espectador:

Naci de la compra del cuerpo de mi madre, y la venta del mío hace que mi piel se sienta como ella aquella noche. A lo largo de mi vida no me he dejado lastimar. He intentado no vincularme para no sufrir. Abandonos de los que no soy culpable, a lo largo de mi infancia y mi adolescencia han hecho que tenga terror a sentir. Y el terror a sentir por su lado, ha conseguido eliminar de mi esa capacidad, un paso adelante, o atrás según se mire, en la evolución. En mi evolución. Que sin querer se encontró

${ }^{8}$ Heterotopia (do grego topos, "lugar", e heterotopia, "outro": "outro lugar") é um conceito forjado por Michel Foucault numa conferência de 1967 intitulada "Des espaces autres". Foucault explicou então que as heterotopias são "tipos de utopias realmente realizadas". 
lo peor de la evolución de otros siendo tan solo un niño. Nací siendo un hijo de puta. Siempre dicen que heredamos cosas de nuestras madres, en mi caso, este es uno de los pocos datos que tengo de la mía. Es mi herencia. Ciento treinta y nueve personas han pasado por mi cuerpo desnudo y herido en esta experiencia, marcada por el dolor, el aprendizaje y la denuncia. Mientras me lamían, me dañaban o me escupían, las lágrimas permanecían en mis ojos, dispuestas a aparecer (AZCONA, 2014, s/p).

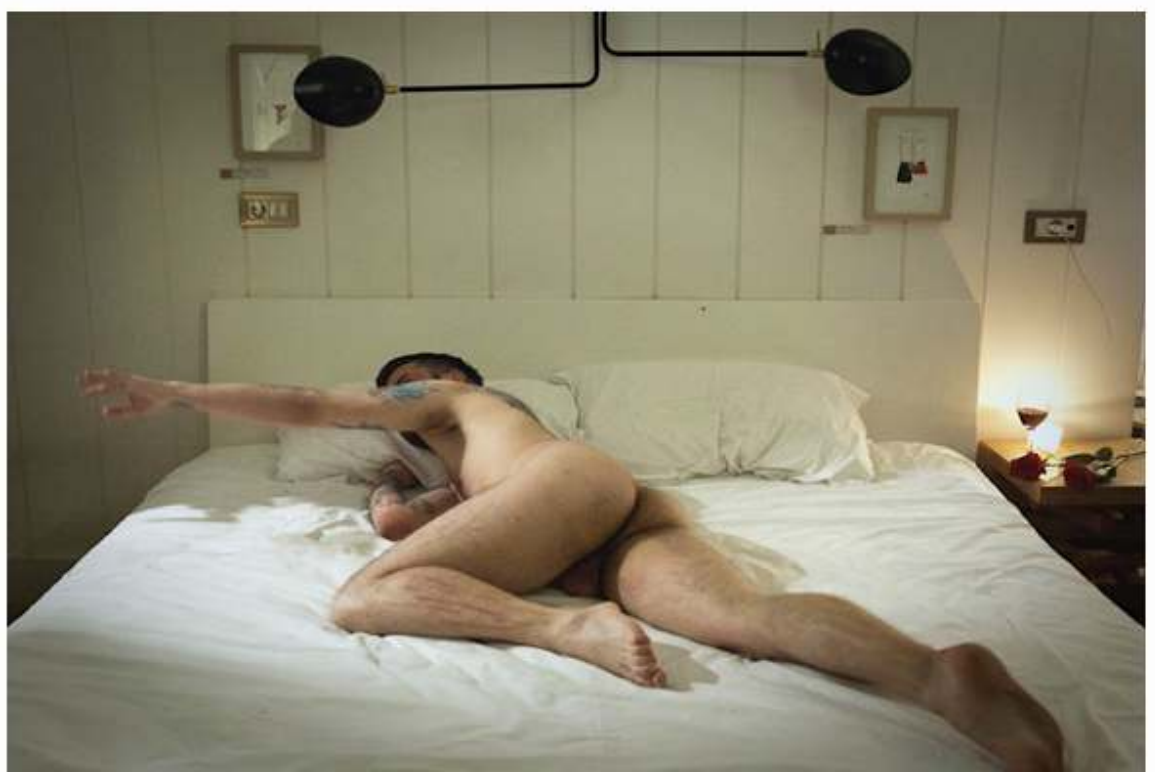

Estudio Abel Azcona twitter

Segundo Azcona, a abordagem foi extremamente simples:

Expus uma cama com o meu corpo nu, e convidei o espectador a ficar comigo na cama durante três minutos por um euro, um dólar ou cem pesos colombianos, dependendo do país. Após o pagamento, o espectador estava livre para exercer ou "atuar" comigo como desejasse. Foi fascinante e surpreendente ver como o espectador estava totalmente ligado, no sexo ou com outros comportamentos... Alguns já estavam à espera da sua vez, sem roupa, para que pudessem aproveitar melhor 
o tempo. Foi um desafio que ainda hoje me surpreende quando vejo algum vídeo das reações da audiência (LAPIDARIO, s/d, s/p).

Foi assim que na Bienal Internacional de Performance de Houston, onde "Empatia e Prostituição" foi apresentada em 2014. Os visitantes ativos", os sexpectadores pagaram pelo corpo de Azcona, ora para sufocá-lo, ora para espancá-lo, mas, também, para acariciá-lo, pular seminus em cima de um colchão, tomar água ou comer um sanduíche ${ }^{10}$, sem dúvidas, uma ação onde o espectador deixa seu papel passivo para trás e desencadeia a ação sobre o artista, agora um objeto, em busca de um curto circuito em processos históricos de normalização daqueles corpos, já que

a normalização é um dos processos mais sutis pelos quais o poder se manifesta no campo da identidade e da diferença. Normalizar significa atribuir a essa identidade todas as características positivas, em relação às quais as outras identidades só podem ser avaliadas de forma negativa. A identidade normal é 'natural', desejável, única" (SILVA, 2014, p. 82).

Azcona é conhecedor de Foucault e reconhece que "o poder ganha impulso pelo seu próprio exercício" (FOUCAULT, 2014, p. 50). Nesse sentido, cultivando a arte do encontro como espanto, seu sexpectador diferentemente do espectador aristotélico (que delegava poderes ao personagem para que este atuasse e pensasse em seu lugar), e igualmente diferente do espectador brechtiniano (que delegava poderes ao personagem para que este atuasse em seu lugar, mas se reservava o direito de pensar por si mesmo, muitas vezes em oposição ao personagem) - age de forma semelhante ao que pensou Augusto Boal sobre o espectador da "Poética do Oprimido", ele "assume um papel protagônico, transforma a ação dramática inicialmente proposta, ensaia soluções possíveis" (BOAL, 2013, p. 124). Desse modo, a

\footnotetext{
${ }^{9}$ A participação do público é um dado importante que permeia a prática artística contemporânea.

10 Partes da performance podem ser vistas aqui: https://artelaguna.world/performance/empatia-yprostitucion-empathy-and-prost.29293/.
} 
performance de Azcona enquanto políticas performativas, concordando com Preciado,

muito além da ressignificação ou da resistência à normatização, se transformarão em um campo de experimentação, um lugar de produção de novas subjetividades e, portanto, uma verdadeira alternativa às formas tradicionais de fazer política" (PRECIADO, 2018b, p. 387).

Tal como para Rancière, é "um teatro sem espectadores, em que os assistentes aprendam em vez de ser seduzidos por imagens, no qual eles se tornem participantes ativos em vez de serem voyeurs passivos" (RANCIÈRE, 2012, p. 9).

Nessa ac ão performática, o sexpectador transforma sua intimidade em extimidade e contribui para a criação de novo material, reformulando o papel de "olhar sem ser visto" para o de "olhar e ser visto", numa nova dinâmica de voyeurismo, a exemplo de Bogotá, onde mais de 50 pessoas passaram pela cama de Azcona e 500 pessoas o assistiram fazendo sexo. Sem dúvida, uma viagem "para pensar o desenraizamento e o trânsito, para pensar um percurso e também um viajante que, necessariamente, se apresentam mais difusos, confusos e plurais do que aqueles das antigas novelas de formação" (LOURO, 2010, p. 204); uma experiência que revela os desejos reprimidos, carentes e a empatia daqueles que compram um corpo esperando que isso os ajudasse a encontrar seus próprios laços. O corpo prostituído de Azcona e o seu uso com propósitos sexuais e de prazer, mas sempre crítico é, além de reflexão sobre a sua/nossa própria experiência pessoal, uma provocação sobre "o sistema de sexo/gênero [que] deve ser reorganizado por meio da ação política” (RUBIN, 2017, p. 55).

Perguntado por Josep Lapidario se, em sua cama houve mais quem o abusasse ou o consolasse, Azcona respondeu:

Había más gente con ganas de ejercer sobre mí violencia, abuso e incluso golpes, pero la verdad es que al final se llegó a un equilibrio... Muchas personas que nunca hubieran tomado parte en ese proyecto vieron esa violencia que se ejercía contra mí y les motivó a participar 
de otros modos: sentándose para hacerme el bien, cantarme, acunarme. Una especie de yin y yang, una alternancia: un cliente bueno y otro malo, uno bueno y otro malo. Había buena gente que se levantaba e intentaba apartar de mí a los que me hacían daño, y no les dejaban volver a sentarse a mi lado. Se creaba de alguna manera un debate alrededor de qué estaba haciendo, los límites del arte... La sala estaba rebosante de energia (LAPIDARIO, s/d, s/p).

Entendemos que, tanto o sexpectador - por razões óbvias -, quanto o voyerista são colocados em cena enquanto corpos estranhos, ou seja, não só o (sex)pectador que tem relações sexuais com Azcona, mas também o lugar ocupado pelo espectador em "Empatia e Prostituição" atua como um ato de sublimação. Ao tomar o que pertence à pornografia e associá-la à empatia que nunca teve da mãe prostituta, Azcona transgride, transforma, sequestra a imagem sexual, que deixa de ser exclusivamente pornográfica, excitante e masturbatória e convida o espectador a apreender imagens pornográficas de uma forma cognitiva, afetiva e intelectual.
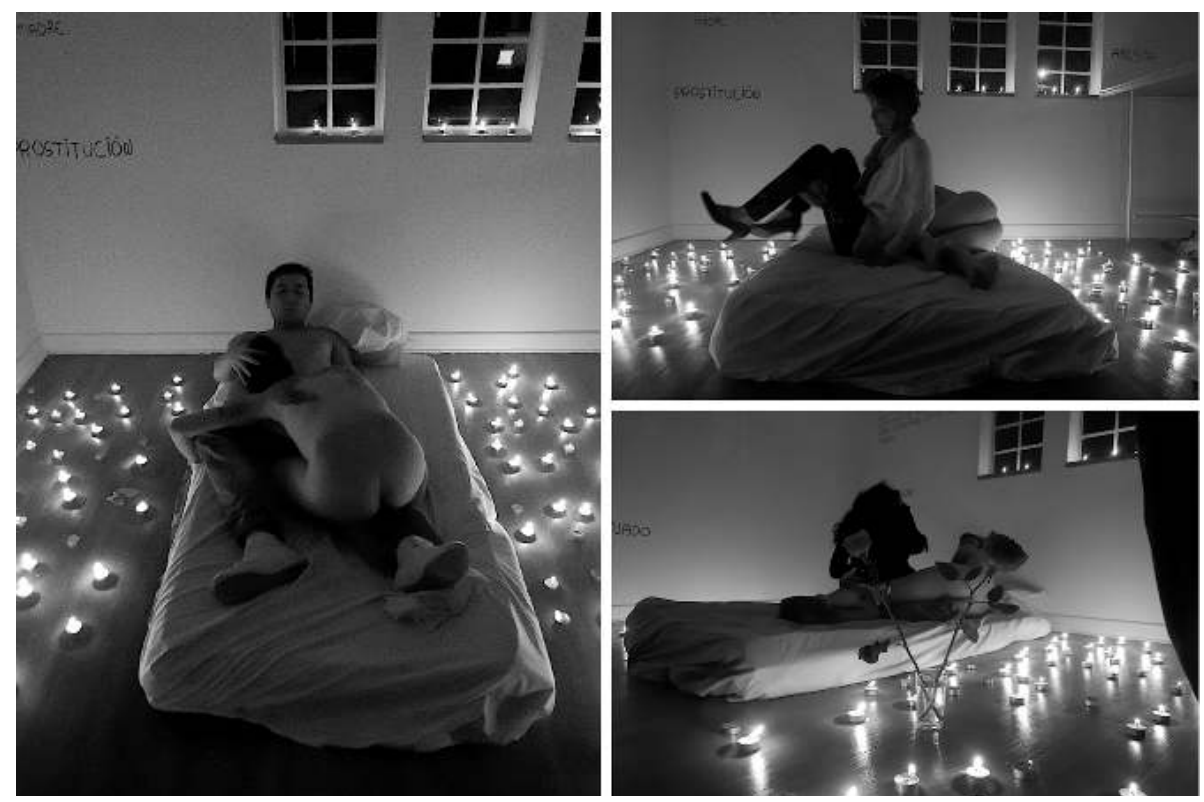

Estudio Abel Azcona twitter 
A ação performática de "Empatia e prostituição" enquanto performance artística, esta "art vivant mis en cuvre par des artistes" (GOLDBERG, 2001, p. 9), equilibrada precariamente entre arte e realidade, é uma instalação que assume a forma de uma improvisação, porque não se trata de interpretar ou representar um papel, não é um ato de imitação, um saberfazer técnico como fazem o atores no cinema e no teatro realistas, mas um verdadeiro acontecimento, único, o que José A. Sánchez (2007) denominara como "Prácticas de lo real en la escena contempora`nea”, que ocorre com:

La superposición de historia y memoria, paralela a la superposición de lo público y lo privado, constituye un punto de partida recurrente en el trabajo escénico de numerosos colectivos latinoamericanos [...] para quienes la restitución de lo acontecido constituye en sí mismo un instrumento de intervención social. La voluntad de dar voz a los otros tiene continuidad en la obra de quienes pretendieron directamente hacer actuar a los otros, por medio de prácticas participativas de carácter revolucionario, o por medio de juegos subversivos, concebidos como ejercicios de afirmación o resiste`ncia (SÁNCHEZ, 2007, p. 6).

Ter nascido do ventre de uma prostituta, tendo sido concebido por engano e a um preço, ter sido rejeitado durante a gravidez e abandonado subsequentemente torna impossível o exercício de empatia com o seu passado. Por isso, Azcona usa a arte como catarse, "seja qual for o canal de expressão, pensamos/criamos porque algo de nossas vidas nos força a fazê-lo para dar conta daquilo que está pedindo passagem em nosso dia a dia - nada a ver com a noção de 'tendência', própria da lógica midiática e seu princípio mercadológico" (ROLNIK, 2006, p. 2).

Neste projeto, o enfant terrible da arte contemporânea espanhola, que tem transformado o seu próprio corpo e a sua presença em território indispensável para a experimentação, se aproxima da eficácia estética, pensada por Rancière (RANCIÈRE, 2012), mesmo que se utilize da sua autobiografia para contar uma história marcada pela dor física e emocional.

11 "arte viva dos artistas" (tradução nossa). 
Suas ações performáticas mais pessoais e reflexivas parecem criadas por necessidade, formulam narrações corporais em torno do auto exploração e da experiência de vida para a busca de um equilíbrio entre a catarse e a saúde mental. Mais tarde, trabalhos com conteúdo mais sócio histórico e político juntaram-se às obras iniciais, com temas facilmente reconhecíveis, como os direitos civis, aborto, abuso colonial, liberdade de expressão e religião, que o afetam diretamente.

Tanto "España os pide perdón”, quanto "Empatia e Prostituição" concordam quando Azcona pensa, que

\begin{abstract}
os artistas de performance y los contemporáneos en general, tenemos el deber de dinamitar "lo bonito", la técnica y el arte sin sentido. Somos artistas, militantes y activistas. La revolución será artística, o no será. Empleamos el cuerpo como elemento de acción, la transgresión como herramienta y la conceptualidad como esencia. Construimos con nuestra experiencia, nuestras heridas y nuestra memoria. Creemos en arte resiliente, un arte de regeneración. Creemos en una regeneración artística (AZCONA, 2017, s/p).
\end{abstract}

Que torne toda injustiça visível através do rito performativo, que suas radicalidades críticas envolvam e comprometam o espectador em repreender e denunciar moralmente uma sociedade colonial, misógina e hipócrita.

É possível dizer, à guisa de conclusão, que as obras aqui abordadas são atos de desobediência e possuem marcadores de caráter autobiográfico e político que expressam uma profunda rebelião contra a sociedade. Azcona, como artista contemporâneo, como um criador de arte política acredita na arte como um instrumento transformador, útil para a revolução micropolítica pensada por Preciado (2018a) anunciada no início deste ensaio. Ainda podemos concluir mais, que acreditar que sua arte é narcisista e exibicionista, que não tem nenhuma carga ou reivindicação política, é saber pouco sobre arte contemporânea. 


\section{Referências}

AZCONA, Abel. Artistas de mierda. Plataforma de Arte Contemporáneo. 2017. Disponível

https://www.plataformadeartecontemporaneo.com/pac/artistas-demierda/. Acesso em: 22 jul. 2020.

AZCONA, Abel. Los pequeños brotes. Espanha: Ed. Dos Bigotes: Edição do Kindle, 2019.

AZCONA, Abel. Empatía y Prostitución en Madrid. In: https://abelazcona.art/Empatiaypros- titucion. 2014.

ALBADRY, Wafaa. Opinion: Let's topple statues to decolonize. 17 jun. 2020. In: https://www.dw.com/en/opinion-lets-topple-statues-to-decolonize/a53840540. Acesso em: 8 jul. 2020.

BOAL, Augusto. Teatro do Oprimido e outras poéticas políticas. São Paulo: Cosac Naify, 2013.

CHIMAMANDA, Ngozi Adichie. O perigo de uma única história. Trad. Julia Romeu. São Paulo: Cia das Letras, 2019.

CASTRO-GÓMES, Santiago. GROSFOGUEL, Ramón (ed.). El giro decolonial: reflexiones para una diversidad epistémica más allá del capitalismo global. Bogotá, Siglo del Hombre Editores. 2007.

CORRONS, Fabrice. Deseo y actuación del sexpectador en el acontecimiento performativo de la era digital. Bulletin of Spanish Studies, 97:1, 51-68, 2020.

DDC. ¿Por qué 'España os pide perdón'? Abel Azcona responde sobre su obra reciente en Cuba. 2 jun. $2020 . \quad$ In: https://diariodecuba.com/cultura/1591114740_22709.html. Acesso em: 8 jul. 2020.

DEBORD, G. A sociedade do espetáculo: comentários sobre a sociedade do espetáculo. Trad. Estela dos Santos Abreu. Rio de Janeiro: Contraponto, 1997.

DUSSEL, Enrique. 1492: O encobrimento do outro: a origem do mito da modernidade. Conferências de Frankfurt. Trad. Jaime A. Clasen. Rio de Janeiro: Petrópolis: Vozes, 1993.

FONSECA, Maria da Penha. Instalações Artísticas e suas contribuições para um Processo Educativo em Arte. Dissertação (Mestrado). Universidade Federal do Espírito Santo (UFES), 2007.

FOUCAULT, Michel. Préface à la transgression. Paris: Ed. Lignes, p. 16-17, 2012. 
FOUCAULT, Michel. Sexo, Poder e Política da Identidade. In: Ditos \& Escritos IX: Genealogia da

ética, subjetividade e sexualidade. Rio de Janeiro: Forense Universitária, 2014.

FOUCAULT, Michel. A grande estrangeira: sobre literatura. Trad. Fernando Scheibe. Belo Horizonte: Autêntica Editora, 2016.

GOLDBERG, Roselee. La Performance du futurisme à nosjours. Trad. Christian-Martin Diebold. Paris: Ed. Thames \& Hudson, 2001.

GUZMÁN, Boris Ramírez. Colonialidad e cis-normatividade. Entrevista con Viviane Vergueiro. 2014. In: https://iberoamericasocial.com/wpcontent/uploads/2015/01/Ram\%C3\%ADrez-B.-2014.-Colonialidad-e-cisnormatividade.-Entrevista-con-Viviane-Vergueiro.pdf. Acesso em: 12 mar. 2020.

HALBERSTAM, Jack. A arte queer do fracasso. Trad. Bhuvi Libanio. Recife: Cepe, 2020.

HÍjAR, Cristina. Arte y política. Revista Arbitrada de Artes Visuales, Tercera Época, enero/junio, 2020.

HUERGA, Yolanda. El perdón de España con temas pasados y presentes. 3 jun. 2020. In: https://www.radiotelevisionmarti.com/a/el-perdón-de-españa-contemas-pasados-y-presentes/266335.html. Acesso em: 8 jul. 2020.

LAPIDARIO, Josep. Abel Azcona: Un artista cómodo no me vale, no es contemporáneo, no es nada. In: https://www.jotdown.es/2015/o9/abelazcona-un-artista-comodo-no-me-vale-no-es-contemporaneo-no-es-nadal. Acesso em: 17 jul.2020.

LARROSA, Jorge. Tremores: escritos sobre experie^ncia. Belo Horizonte: Aute`ntica Editora, 2015.

LOPES, Denilson. Prefácio. A força do fracasso. In: HALBERSTAM, Jack. Trad. Bhuvi Libanio. Recife: Cepe, 2020.

LLOPIS, Néstor. Abel Azcona. In: https://abelazcona.art/empatiayprostitucion. Acesso em: 12 jul. 2020.

LOURO, Guacira Lopes. Viajantes Pós-Modernos II. In: LOPES, Luiz Paulo da Moita;

BASTOS, Liliana Cabral (Org.). Para além da identidade: fluxos, movimentos e trânsitos. Belo Horizonte: Editora UFMG, 2010. 
Mídia Ninja. Derrubar estátuas, reescrever a História. 22 jun. 2020. In: https://domtotal.com/super-dom/1001/2020/06/derrubar-estatuasreescrever-a-historia/. Acesso em: 8 jul. 2020.

PARDO, Sara. “España os pide perdón”, la disculpa por el colonialismo. 5 jun. 2020. In: https://elcofresuena.es/arte/espana-os-pide-perdon-la-disculpapor-el-colonialismo/. Acesso em 08 jul. 2020.

PRECIADO, Paul B. La izquierda bajo la piel. Um prólogo para Suely Rolnik. In: Esferas da insurreição. Nora para uma vida não cafetinada. São Paulo: n-1 edições, 2018a.

PRECIADO, Paul B. Texto Junkie. Sexo, drogas e biopolítica na era farmacopornográfica. Trad. Maria Paula Gurgel Ribeiro. São Paulo: n-1 edições, 2018b.

RANCIÈRE, Jacques. A partilha do sensível. Trad. Mônica Costa Netto. São Paulo: EXO experimental org.; Ed. 34, 2009.

RANCIÈRE, Jacques. O espectador emancipado. São Paulo: WMF; Martins Fontes, 2012.

ROLNIK, Suely. Geopolítica da cafetinagen. In: Fazendo Rizoma: pensamentos contemporâneos. (Org.). FURTADO, Beatriz; LINS, Daniel. São Paulo: hedra, 2008.

ROLNIK, Suely. Cartografia sentimental: transformações contemporâneas do desejo. Porto Alegre: Sulina; Editora da UFRGS, 2006.

RUBIN, Gayle. Políticas do sexo. Trad. Jamille Pinheiro Dias. São Paulo: Ubu Editora, 2017.

SANCHEZ, José Anto`nio. Prácticas de lo real en la es- cena contempora`^nea. Madrid, Visor Libros, $2007 . \quad$ In: http://territorioteatral.org.ar/html.2/dossier/pdf/n3_ol.pdf. Acesso em: 12 jul. 2020.

SEGATO, Rita. Contra-Pedagogías de la crueldade. Cidade Auto`noma de Bienos Aires: Prometeo Libros, 2018.

SILVA, Tomaz Tadeu da. (Org.). Identidade e diferença: a perspectiva dos estudos culturais. 15. ed. Petrópolis: Vozes, 2014.

SIMAS, Luiz Antonio; RUFINO, Luiz. Flecha no tempo. Rio de Janeiro: Mórula, 2019. 
STREVA, Juliana Moreira. Colonialidade do ser e corporalidade: o racismo brasileiro por uma lente descolonial. Revista Antropolítica, n. 40, Niterói, 2016, p. 20-53.

THÜRLER, Djalma; WOYDA, Duda; VALOIS, Olinson. (cu)nhantã tem, (cu)rumim também: políticas de subjetivação em imagens de Abel Azcona. Revista Digital do LAV, vol. 13, n. 2, mai./ago, 2020, p. 76 -99.

Recebido em 29 de julho de 2020.

Aceito em 30 de outubro de 2020. 